\title{
An Empirical Study of Portfolio Selection for Optimally Hedged Portfolios
}

\author{
C. J. Adcock \\ The University of Sheffield, UK
}

This paper reports a study into the performance of currency-hedged portfolios constructed using mean-variance optimization methods. The method is to carry out optimization relative to a benchmark portfolio, which consists of the real assets, and simultaneously to determine the optimal exposures to each currency future. This is done at various levels of risk along the efficient frontier. A study into a portfolio of international stock and bond indices viewed from a US Dollar perspective indicates that, for the period studied, optimal currency hedging has the potential to add value in terms of additional expected return and excess return on a risk-adjusted basis. The results also demonstrate the superiority of strategies in which the hedge ratio is optimally determined over those with a fixed hedge ratio (JEL G11).

Keywords: exchange rate risk, currency hedging, mean-variance optimization.

\section{Introduction}

International investment offers the prospect of improved diversification, even though investors are exposed to exchange rate risk. It is well known that hedging the currency risk can lead to improved portfolio performance as well as removing most if not all of the exchange rate risk. There have been numerous studies of the impact of hedging currency risk, particularly within the framework of mean-variance portfolio selection. Examples of some of the investigations into the

*This study uses data and forecasts provided by Dupont Capital Management. Their permission to use this information and the assistance provided by Paul Bosse and Mark Swankoski is gratefully acknowledged.

(Multinational Finance Journal, 2003, vol. 7, no. 1 \& 2, pp. 83-106)

(CMultinational Finance Society, a nonprofit corporation. All rights reserved.

DOI: $10.17578 / 7-1 / 2-4$ 
benefits of hedging include papers by Eun and Resnick (1988) Glen and Jorion (1993) and De Roon, Nijman and Werker (2001a, b).

The objective of this paper is to report an investigation into the use of mean-variance methods to construct optimal portfolios consisting of both real assets and the currency futures used to hedge exchange rate risk. The method is to carry out optimization relative to a benchmark portfolio, which consists of the real assets, and simultaneously to determine the optimal exposures to each currency future. This is done at various levels of risk along the efficient frontier. The paper reports the performance of several optimally hedged international portfolios, viewed from the perspective of a US based investor. The real assets included in the portfolio are stock and bond indices on 14 international markets as well as the US. The results reported in this study are based on portfolio optimizations that assume realistic constraints on holdings. This is done both to generate results that may be of practical use and in keeping with the view, see for example Frost \& Savarino (1988), that the use of suitable constraints will improve portfolio performance. The paper also reports an extension to the efficient set mathematics of hedged portfolios, which is similar to a result of De Roon, Nijman and Werker (2001a). These both serve the purpose of providing some insights into the likely effects of currency hedging on the portfolio.

The results of this paper suggest that optimal currency hedging has the potential to add value in terms of both additional expected return and excess return on a risk-adjusted basis. The results also demonstrate the superiority of strategies in which the hedge ratio is optimally determined. However, it should be noted that the results described in the paper are a consequence of the inputs. As Michaud (1998, page 62) notes, good forecasts are an essential pre-requisite to subsequent good portfolio performance.

The structure of the paper is as follows. Section II describes the main assumptions made, notation used and summarises the key formulae that are used. Section III describes efficient set mathematics for hedged portfolios. This is supported by a technical appendix. Section IV summarises the portfolio construction objectives used in the study. Section V describes the performance of portfolios built using a number of strategies designed to investigate the effect of currency hedging. Section VI concludes. Notation is that in common use. 


\section{Notation and Portfolio Selection Method}

A universe of $N_{R}$ real assets and $N_{C}$ currencies is considered. Normally $N_{C}$ is less than $N_{R}$, but for ease of exposition it is assumed in this section that they are the same and both equal to $N$. The unhedged return on an overseas investment is written as:

$$
R_{R}=R_{R}+R_{S C}+R_{L} R_{S C}
$$

where $R_{L}$ is the local market return and $R_{S C}$ is the spot return on the currency. The return on a futures position in the currency is approximated in the usual way by:

$$
R_{C}=R_{S C}+\left(I R_{L}-I R_{B}\right)=R_{S C}+R_{I}
$$

say where $I R_{L}$ and $I R_{B}$ are the interest rates prevailing in the local and home markets, respectively and $R_{I}$ is the interest rate differential. For a given hedge ratio $h$, the hedged return on the combined position may be written as: ${ }^{1}$

$$
R_{H}=R_{R}-h R_{C}
$$

The conventional approach to the construction of the optimal hedge, see for example Solnik (1999, p. 489), ratio is to minimise the variance of $R_{H}$. In this case, the optimal hedge ratio is:

$$
h^{*}=\frac{\operatorname{COV}\left[R_{R}, R_{c}\right]}{\operatorname{VAR}\left[R_{C}\right]} .
$$

That is, the hedge ratio that minimises the variance of hedged returns is the beta of unhedged returns with respect to the currency futures return. This idea may be taken as a means of motivating the use of mean-variance optimization for the construction of optimally hedged portfolios.

Using the above notation with the addition of an subscript $i$ to denote asset $i$, the return on a hedged portfolio is:

1. This treatment is equivalent to assuming that the initial investment is hedged. This differs slightly from the treatment in Eun and Resnick (1988) who assume that the expected wealth at the end of the holding period is hedged. 


$$
R_{P}=\sum_{i=1}^{N} w_{R, i} R_{R, i}+\sum_{i=1}^{N} w_{C, i} R_{C, i}
$$

where $\left\{w_{R, i}\right\}$ are the weights on the real assets and $\left\{w_{C, i}\right\}$ are the weights on the currencies. The $\left\{R_{R, i}\right\}$ are unhedged returns and the $\left\{R_{C, i}\right\}$ are the returns from the currency positions. This expression is non-linear in the underlying assets through its functional dependence on the product terms $R_{L, i} R_{S C, i}$.

The vectors of expected returns corresponding to the $\left\{R_{L, i}\right\},\left\{R_{S C, i}\right\}$ and $\left\{R_{I, i}\right\}$ are written as $\mu_{L}, \mu_{C}$ and $\mu_{I}$ respectively and the variancecovariance $(V C)$ matrix is:

$$
\left[\begin{array}{lll}
V_{L L} & V_{C L} & V_{L I} \\
V_{C L} & V_{C C} & V_{C I} \\
V_{I L} & V_{I C} & V_{I I}
\end{array}\right]=\mathbf{V} .
$$

Element $(i, j)$ of a sub-matrix $V_{a b}$ is denoted $V_{a b}{ }^{i j}$. The two sets of weights $\left\{w_{R, i}\right\}$ and $\left\{w_{C, i}\right\}$ are denoted by the vectors $w_{R}$ and $w_{C}$ respectively. In this notation, expected portfolio return is:

$$
E\left[R_{P}\right]=w_{r}^{T}\left[\gamma+\mu_{L}+\mu_{C}+\delta\right]+w_{C}^{T}\left[\mu_{C}+\mu_{I}\right],
$$

where $\gamma$ is the vector of covariances between asset $i$ and currency $i$ :

$$
\gamma=\left\{V_{C R}^{i i}\right\}
$$

and $\delta$ is the vector containing the product of the corresponding expected returns: ${ }^{2}$

$$
\delta=\left\{\mu_{L, i} \mu_{C, i}\right\}
$$

The exact variance of portfolio return is more complex. However, following Eun and Resnick(1988), for practical purposes portfolio variance is well approximated by:

2. This result is standard and only requires that the corresponding moments of the underlying distribution exist. 
where:

$$
V\left[R_{p}\right]=\mathbf{w}^{\mathbf{T}} \mathbf{K}^{\mathrm{T}} \mathbf{V K w},
$$

$$
\mathbf{K}=\left[\begin{array}{cc}
I & 0_{N, N} \\
I & I \\
0_{N, N} & I
\end{array}\right], \mathbf{w}=\left[\begin{array}{l}
w_{R} \\
w_{C}
\end{array}\right],
$$

and where $I$ is an $N$ by $N$ unit matrix and $0_{N, N}$ is an $N$ by $N$ matrix of zeros. The above formula for mean and variance are developments of those in Rustem (1997), who is concerned with the return on an unhedged portfolio, that is a portfolio based only on the $\left\{R_{R, i}\right\}$ in the current notation. These expressions require no assumptions about the underlying probability distribution of returns on both assets and currencies, except that the individual expectations and covariances in the formulae above must all exist.

When existence is assumed, both $E\left[R_{p}\right]$ and $V\left[R_{p}\right]$ may be consistently estimated in a number of ways. It is then possible to perform mean-variance portfolio selection. However, the non-linearity in the definition above means that the hedged portfolio return $R_{P}$ may not have a normal distribution, even when the underlying assets and currency returns themselves are normal. Briefly, it may be noted that $R_{P}$ may be written as an quadratic form in normal variables, see, for example, Johnson and Kotz (1970, chapter 29) for details. The probability distribution has a density function that is too complicated for exact computation. However, in the underlying normal case, the exact moments of $R_{P}$ may be extracted from the moment generating function. Detailed investigation of this issue is beyond the scope of this paper. ${ }^{3}$

A more serious concern is that the probability distributions of the underlying assets are not normal. The diagnostics reported in section 4 confirm the presence of both skewness and kurtosis. Following Chamberlain (1983) and Ingersoll (1987, chapter 4), the view taken in this paper is that kurtosis per se does not invalidate the use of meanvariance portfolio selection as long as (a) returns can be modelled using a member of the elliptically symmetric class of distributions and (b) the relevant variance exists. ${ }^{4}$ There is ample empirical evidence that

3. A technical appendix which describes the extraction of the moments is available on request.

4. This is not a demanding requirement as long as the investor is prepared to use the 
supports both these points. Aparicio and Estrada (2001), for example, is a recent contribution to the literature on the use of Student's $t$ distribution, which began with the well-known papers by Praetz (1972) and Blattberg and Gonedes (1974). Dealing with skewness is more problematic. In this paper, common practice is followed and it is assumed that the investor is content to ignore skewness or that the portfolio will be sufficiently well diversified and that, as a result, skewness is negligible.

\section{Efficient Set Mathematics}

Efficient set mathematics typically considers the maximisation of the expected value of a quadratic utility function, subject only to the budget constraint. For portfolios in which there are currencies, the budget constraint only applies to the real assets, ie to the $\left\{R_{R, i}\right\}$. The properties of the efficient set in the context of portfolios with currency hedging have been reported in several papers that address mean-variance spanning. These include Jobson and Korkie (1984), Huberman and Kandel (1987) and De Roon, Nijman and Werker (2001a, b). The second and third papers describe the properties of excess return portfolios that are constructed relative to a zero-beta portfolio. As De Roon, Nijman and Werker (2001a) note, the zero beta portfolio is dependent on the level of risk appetite of the investor as well as the utility function. In this section, the efficient set mathematics for the whole of the efficient frontier are described. This is more appropriate for the task in hand in this paper, which is to construct total return portfolios corresponding to a range of levels of risk appetite.

The derivation of the efficient set is based on the above definition of portfolio return, the exact expected return and approximate variance. The two sets of observed returns $\left\{R_{R, i}\right\}$ and $\left\{R_{C, i}\right\}$ are denoted by the vectors $R_{R}$ and $R_{C}$, respectively. The corresponding vectors of expected returns are $\mu_{R}$ and $\mu_{C}{ }^{5}$ The $2 N$ by $2 N$ variance-covariance matrix is $V$, which is written in the standard partitioned form:

symmetry matrix.

5. Note that in this seciton $\mu_{C}$ denotes the expected return on the currency positions. This differs slightly from the definition in section III. However, no confusion should arise. 


$$
V=\left[\begin{array}{ll}
V_{R R} & V_{R C} \\
V_{C R} & V_{C C}
\end{array}\right] .
$$

The portfolio selection criterion is the usual mean-variance method of maximising the quadratic utility function:

$$
\theta E\left[R_{p}\right]-\frac{1}{2} \operatorname{VAR}\left[R_{p}\right]
$$

where $\theta \geq 0$ denotes the risk appetite of the investor. To derive the efficient set portfolio, expected utility maximisation is subject only to the budget constraint on the weights $\left\{w_{R, i}\right\}$. The first order conditions are:

$$
\theta\left[\begin{array}{l}
\mu_{R} \\
\mu_{C}
\end{array}\right]-\left[\begin{array}{ll}
V_{R R} & V_{R C} \\
V_{C R} & V_{C C}
\end{array}\right]\left[\begin{array}{l}
w_{R} \\
w_{C}
\end{array}\right]-\lambda\left[\begin{array}{l}
1 \\
0
\end{array}\right]=\left[\begin{array}{l}
0 \\
0
\end{array}\right],
$$

where 1 is an $N$ vector of ones and $\lambda$ is the Lagrange multiplier. The optimal vector of real weights is the solution to:

$$
\theta\left\{\mu_{R}-V_{R C} V_{C C}^{-1} \mu_{C}\right\}-\left\{V_{R R}-V_{R C} V_{C C}^{-1} V_{C R}\right\} w_{R}-\lambda 1=0
$$

That is, the weights for real assets are based on (a) the $V C$ matrix of returns on real assets obtained by conditioning on the currency returns:

$$
V_{R R}-V_{C C}^{-1} V_{C R}=V_{R \mid C}
$$

and (b) the vector of returns:

$$
\left\{\mu_{R}-V_{R C} V_{C C}^{-1} \mu_{C}\right\}=\alpha_{R \mid C}
$$

The term $\alpha_{R \mid C}$ is the generalised Jensen measure, ie the intercept in the multivariate regression of real returns $R_{R}$ on the currencies $R_{C}$. The corresponding vector of currency weights is:

$$
w_{C}=\theta V_{C C}^{-1} \mu_{V C}-V_{C C}^{-1} V_{C R} w_{R}
$$


There are several points to note. First, unless the cross covariances between real assets and currencies are all zero, the minimum variance portfolio always consists of a combined position in both real assets and currencies. Specifically, when $\theta=0$, the components of the minimum variance portfolio are:

$$
\begin{aligned}
& w_{R, 0}=\frac{1}{1^{T} V_{R \mid C}^{-1} 1} V_{R \mid C}^{-1} 1, \\
& w_{C, 0}=-V_{C C}^{-1} V_{C R} w_{R, 0} .
\end{aligned}
$$

Second, if:

$$
\alpha_{R \mid C}=0
$$

then the weights for the real assets will always equal those in $w_{R, 0}$ regardless of the risk appetite of the investor. Thirdly, the weights for the currency component will in general vary with risk appetite. However, as noted in De Roon, Nijman and Werker (2001a), if the Jensen measure for the regression of currencies on the real assets:

$$
\alpha_{C \mid R}=\mu_{C}-V_{C R} V_{R R}^{-1} \mu_{R}=0 .
$$

Then the currency weights are always equal to the currency component of the minimum variance portfolio regardless of the degree of risk appetite. Parenthetically, it may be noted that use of the decompositions of the inverse of the variance-covariance matrix often has the potential to give insights into portfolio structure - see Stevens(1998) for example.

In practice, portfolio selection will always be performed subject to inequality constraints. These will generally apply to the real assets in the portfolio although, as described in section 4 , there are also likely to be constraints on the currency exposures too. Depending on the level of risk appetite, the elements of the expected return vectors and the elements of the overall $V C$ matrix, the constraints will, as is usual, change the vector of optimal weights. However, the real weights and hence the currency weights are determined by $V_{R \mid C}$, the conditional $V C$ 
matrix. ${ }^{6}$

In section 4, optimization relative to a benchmark portfolio, which consists of specified weights in the real assets but not the currencies, is considered. At zero risk appetite, ie $\theta=0$, the optimization process will produce a portfolio in which the real weights equal those of the benchmark and there are no currency exposures.

It is also useful to be able to compare optimally hedged portfolios at a given level of risk $\theta$ with the portfolios that arise when the hedge ratio is fixed, at $h$ say. In the appendix, it is shown that there the variance of a portfolio with a fixed hedge ratio will be greater [less] than the corresponding variance of an optimally hedged portfolio if the quantity:

$$
\left(h-h_{0}\right)\left(h+h_{0}-2 h_{M V}\right)
$$

is positive [negative], where $h_{0}$ is the hedge ratio for the optimally hedged portfolio at risk $\theta$ and $h_{M V}$ is the hedge ratio of the optimally hedged portfolio at risk zero, ie the optimal minimum variance hedge ratio.

\section{Portfolio Design Objectives and Input}

The objective of this study is to investigate the benefits of optimal currency hedging. This is done using mean variance optimization in conjunction with portfolio expected return and variance as defined in section 2 . The study is based on 31 real assets and 7 currencies. The real assets are stock and bond indices for 15 non-US markets together with the return on a US cash instrument. The aim of the investigation is to examine the effect of two currency hedging strategies.

First, a fixed hedge ratio of one is imposed. This is a constraint on the total currency exposure which, in the above notation, is:

6. This interpretation is dependent on the convention adopted for the elements of the inverse of a partitioned matrix. Specifically, the sub-matrix of $V^{-1}$ corresponding to the real assets is written as $V_{R \mid C}$. The other convention, which is to use $V_{C \mid R}$ for the sub-matrix of $V^{-1}$ corresponding to the currencies, is that used in De Roon, Nijman and Werker (2001a). This leads to slightly different representations of the portfolio weights, but does not change their basic properties. 
TABLE 1. Markets and Currencies

\begin{tabular}{|c|c|}
\hline Country & Currency \\
\hline Australia & $\mathrm{A} \$$ \\
\hline Austria & Euro \\
\hline Belgium & Euro \\
\hline Canada & $\mathrm{C} \$$ \\
\hline Denmark & Euro \\
\hline France & Euro \\
\hline Germany & Euro \\
\hline Italy & Euro \\
\hline Japan & Yen \\
\hline Netherlands & Euro \\
\hline Norway & Norwegian Kroner \\
\hline Sweden & Euro \\
\hline Switzerland & Swiss Franc \\
\hline United Kingdom & Pound Sterling \\
\hline United States & US\$ \\
\hline
\end{tabular}

Under this strategy, the objective of the optimization process is to determine the optimal choice of currency futures positions subject to the above restriction. The second strategy is to allow the optimization process to determine the currency weights without any restrictions, thus giving a truly optimally hedged portfolio.

These two strategies are implemented by carrying out optimization relative to a benchmark portfolio. This specifies weights for the real assets.

The 15 markets and currencies are as listed in Table 1. In the tables that follow, stock indices are numbered 1 through 15, bond indices 16 through 30 and currencies are numbered 1 through 7.

The stock index returns are derived from the relevant MSCI indices. The bond returns were derived from JP Morgan ten year bond indices. Foreign exchange returns and interest rates are from Datastream. The study is based on monthly return data from February, 1978 to July, 1999. Unhedged returns on the 30 overseas assets and returns on the currency 
forwards were computed using the formulae in section 2 . The return on the EURO was proxied by using the Deutschemark. As well as historic returns, the study uses time series of one-month ahead forecast of future expected returns of real assets and currencies. These cover the same time period and were generated by a number of econometric models. ${ }^{7}$ The historic returns were used in conjunction with exponential smoothing to generate a one-month ahead estimate of the overall 38 by $38 \mathrm{VC}$ matrix of returns. This was updated each month.

The optimization approach used in this paper is the standard backtesting method. ${ }^{8}$ Each month, the forecast returns and $V C$ matrix are used as input to the portfolio selection based on mean-variance optimization. The ex-post return is computed using the actual returns for the month in question. A time series of portfolio performance is thus accumulated for analysis. Portfolio simulations are carried out at several points on the efficient frontier corresponding to increasing levels of risk appetite.

In order to simulate the effect of optimal currency hedging on a realistic portfolio construction strategy, several additional constraint were imposed. First, real assets were constrained to be within $\pm 100 \%$ of their corresponding benchmark weight, ie:

$$
0 \leq w_{R, i} \leq 2 b_{i}
$$

Second, naked currency exposures were not allowed. That is, a position was allowed only for currencies for which there is a holding in the underlying asset.

Basic statistics for historical returns for the period February, 1978 to July, 1999 are shown in table 2.

The Durbin-Watson statistics indicates a lack of first order serial correlation for all assets. The Bera-Jarque test for normality and its associated $p$-value are shown in the last two columns of the table. These indicate departures from normality 5 out of the 7 currencies and for 26 out of the 30 real assets. Also shown in the table is the decomposition of the Bera-Jarque test into its skewness and kurtosis components and their

7. The data and forecasts were provided by Dupont Capital Management. The forecasting methods are confidential. This does not affect the objectives of this paper, which is to report the efficacy of various hedging strategies.

8. The portfolio simulations were carried out using software written in S-Plus. 


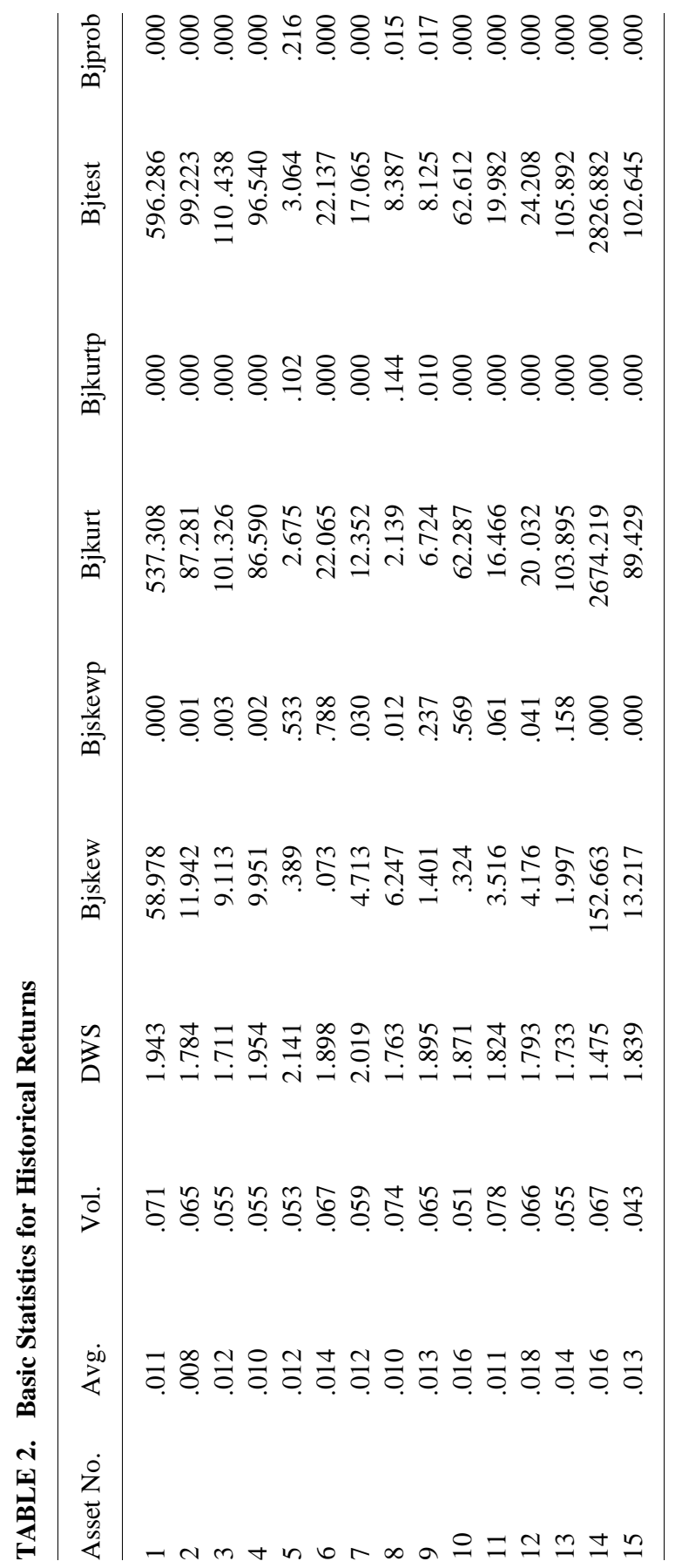




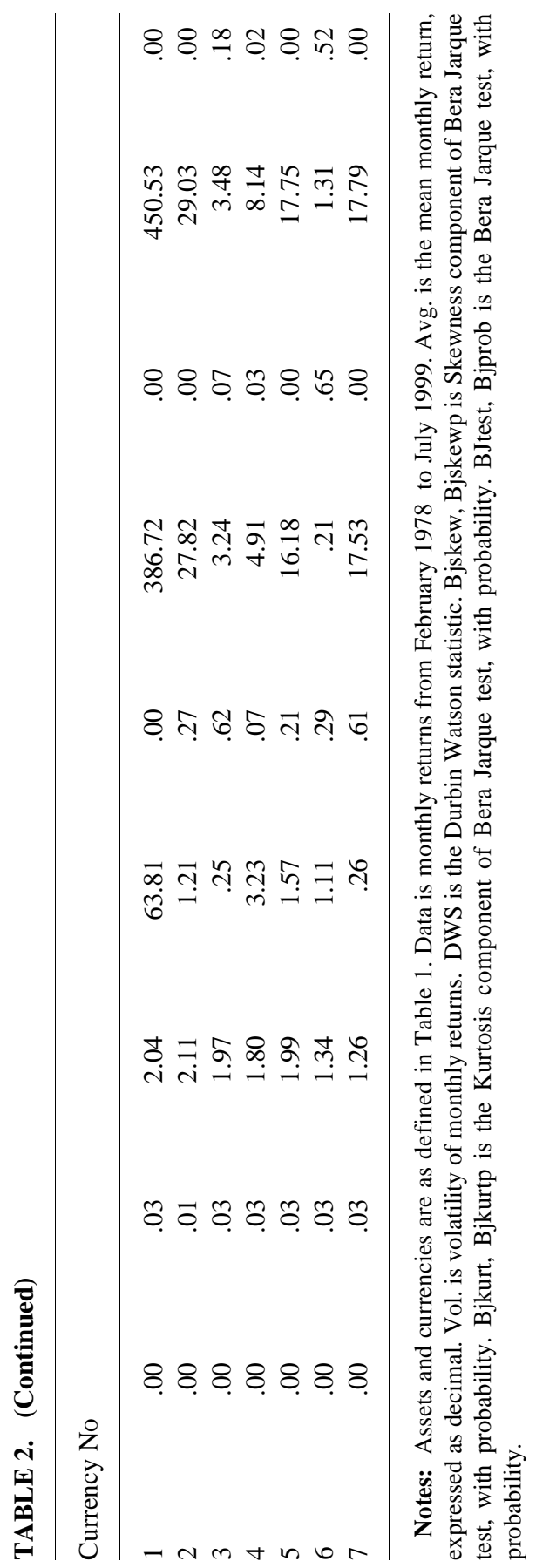


corresponding $p$-values. Under the null hypothesis of normality, these are independently distributed as $C h i$-squared variables with 1 degree of freedom. This decomposition indicates that there is one currency and 13 real assets that exhibit skewness. Only 4 assets and one currency fail to exhibit kurtosis. ${ }^{9}$ As noted in section II, this casts some doubt on the underlying theoretical model for returns on both real assets and currencies. This issue falls outside the scope of this paper and is listed in the conclusions as a topic for further study.

Table 3 shows basic statistics for forecasts. As might be expected, the forecasts exhibit strong first order serial correlation. To reduce the number of columns in the table, only the decompositions of the BeraJarque statistic and their corresponding $p$-values are shown. Only one forecast exhibits skewness, although there is evidence of significant kurtosis in 17 out of 30 real assets and 6 out of 7 seven currencies. ${ }^{10}$ As noted above, the results of these tests cast some doubt on the underlying assumption of normality.

\section{Results}

Table 4 shows statistics derived from the estimated values of the generalised Jensen measures $\alpha_{C \mid R}$ and $\alpha_{R \mid C}$. These vectors were consistently estimated using the corresponding sample quantities based on the whole data set. The table shows the means of each vector and the mean of the absolute values of each element. Even though these quantities are numerically small, the $F$-test due to Gibbons, Ross and Shanken (1989) indicates that currency hedging will have an effect on the weights of the real assets and that the weights of the total portfolio will change with an investor's risk appetite. It should be noted that the F statistics should be interpreted with some caution, see footnote 7 of Glen and Jorion (1993). However, the $p$-values associated with the $F$ ratios in Table 4 are very small. ${ }^{11}$

9. The significance level assumed in the text was $5 \%$. The decomposition gives tests with low powerm but plays a useful diagnostic role.

10. Currency 5 , with a $p$-value of 0.051 is included.

11. The test has been carried out separately for each alpha. As the test statistics are correlated, this is an approximation, but it analogous to the usual battery of $t$-tests in regression. 


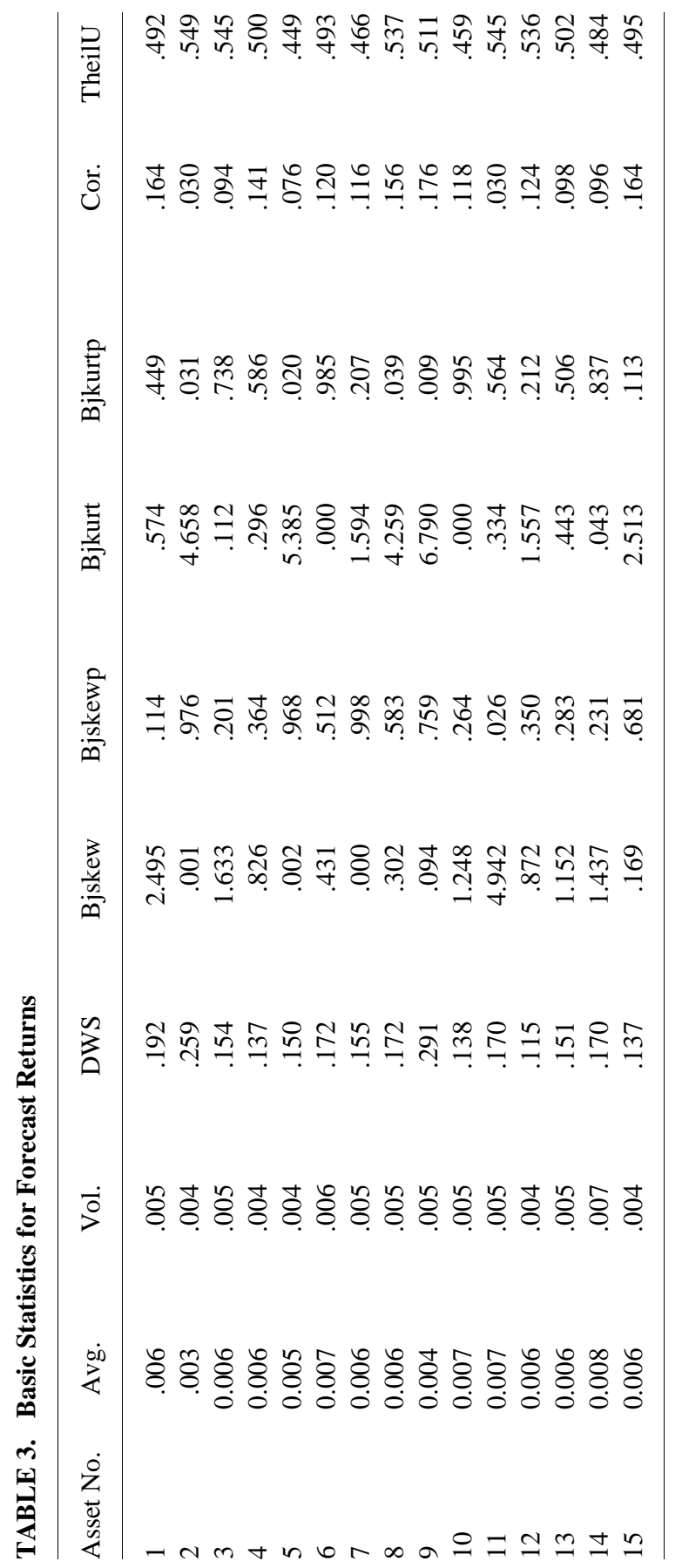




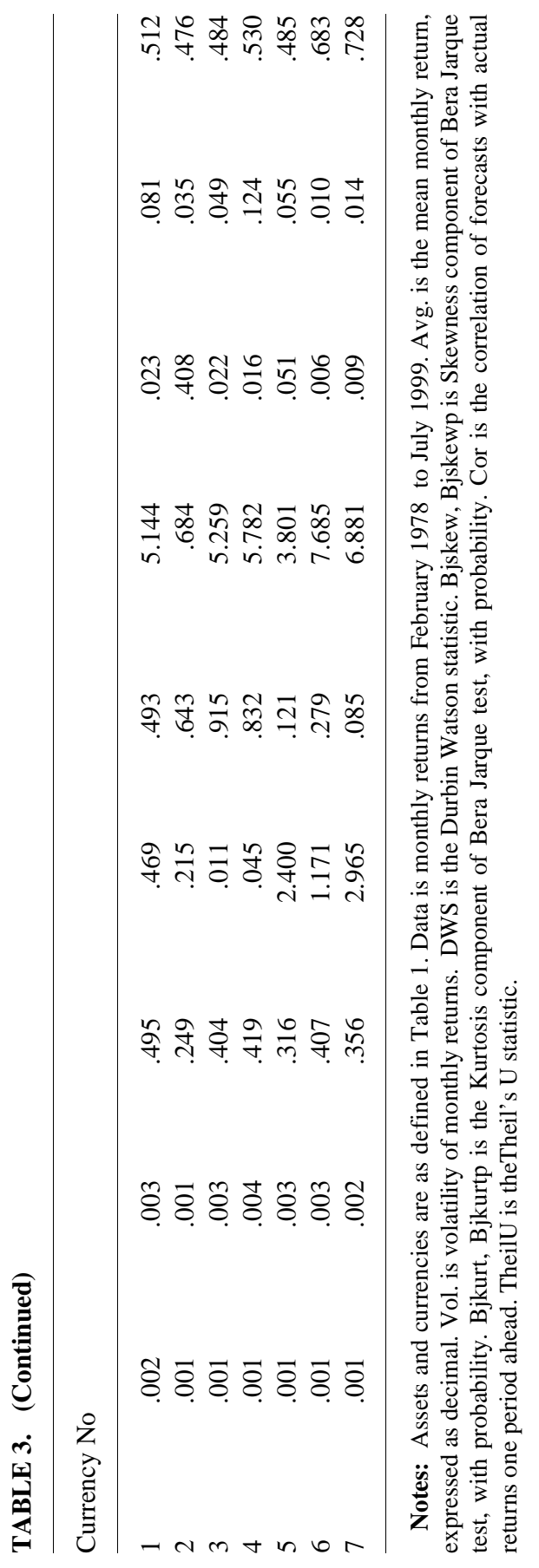


TABLE 4. Estimated Generalized Jensen Measures

\begin{tabular}{lcccc}
\hline & Mean & Mean Absolute & Volatility & $F$-ratio \\
\hline$\alpha_{C \mid R}$ & .004 & .004 & .002 & 24.8 \\
$\alpha_{C \mid R}$ & .001 & .001 & .003 & 10.3 \\
\hline
\end{tabular}

Note: Assets and currencies are as defined in table 1. Data is monthly returns from February, 1978 to July, 1999.

Table 5 shows ex-post summary statistics from three sets of simulations: (1) with no currency hedge, (2) an overall hedge ratio set to -1 , but with individual currency weights determined by the optimization process and (3) optimal hedging with the currency weights and hedge ratio determined by the optimizer. As described in section 4 , simulations are carried out at several points of the efficient frontier. All three sets of simulations indicate that the forecasts used do possess sufficient signal to allow the construction of acceptable portfolios. As is usually the case with such simulations, the tracking error of excess return measured relative to the return on the benchmark portfolio increases with risk, as does portfolio turnover.

For sets 1 and 3, the optimal trade-off between excess return and risk occurs at low levels of risk appetite. For set 2, the simulations with a fixed hedge ratio, the risk-return trade-off increases with risk appetite. It remains lower than the corresponding levels for sets 1 and 3 and is also lower than the best levels achieved for these sets. The excess return of set 2 is superior to that of an unhedged portfolio at the same level of risk appetite. However, this is at the expense of an increased level of tracking error. On the basis of these simulations, it is reasonable to conclude that optimal hedging has much to offer over the used of a fixed hedge ratio. For this data the average value of the hedge ratio for the minimum variance portfolio is $-26.8 \%$. The increased variance of the fixed hedge portfolio is confirmed by the condition in section 3 , which takes a positive value. It should be noted that these findings are contrary to those in Eun and Resnick (1988) who explain that a hedged portfolio should exhibit lower variance than its unhedged counterpart. However, as they indicate, this is a consequence of the covariances between real assets and currencies. The different results reported here are attributed to the changing structure of the overall $V C$ matrix of returns on assets and currencies. 
TABLE 5. Comparative Ex-post Statistics for Portfolio Simulations

\begin{tabular}{|c|c|c|c|c|c|c|}
\hline Risk & $\begin{array}{l}\text { Monthly } \\
\text { Portfolio } \\
\text { Returns }\end{array}$ & $\begin{array}{l}\text { Excess } \\
\text { Return }\end{array}$ & $\begin{array}{l}\text { Tracking } \\
\text { Error of } \\
\text { Turnover }\end{array}$ & $\begin{array}{l}\text { Hedge Ratio } \\
\text { (Set } 3 \text { only) }\end{array}$ & $\begin{array}{l}\text { Annual } \\
\text { Excess } \\
\text { Return }\end{array}$ & $\begin{array}{l}\text { Risk- } \\
\text { Return } \\
\text { Ratio }\end{array}$ \\
\hline \multicolumn{7}{|c|}{ Portfolio of real assets only } \\
\hline 0. & 1.1100 & .0000 & .0000 & 2.3000 & .00 & N/A \\
\hline 0.025 & 1.1730 & .0630 & .1330 & 6.7400 & .76 & 164.09 \\
\hline 0.05 & 1.2030 & .0930 & .2230 & 9.6400 & 1.12 & 144.47 \\
\hline 0.1 & 1.2440 & .1340 & .3650 & 13.5500 & 1.62 & 127.18 \\
\hline 0.25 & 1.3130 & .2030 & .5950 & 19.1800 & 2.46 & 118.19 \\
\hline 0.5 & 1.3930 & .2830 & .7820 & 23.9800 & 3.45 & 125.36 \\
\hline 1 & 1.4680 & .3580 & .9840 & 27.0700 & 4.38 & 126.03 \\
\hline \multicolumn{7}{|c|}{ Portfolio with fixed hedge ratio } \\
\hline 0 & 1.2100 & .1000 & 2.2150 & 4.0000 & 1.21 & 15.64 \\
\hline 0.025 & 1.2170 & .1070 & 2.0580 & 5.5980 & 1.29 & 18.01 \\
\hline 0.05 & 1.2570 & .1470 & 2.0680 & 8.5020 & 1.78 & 24.62 \\
\hline 0.1 & 1.3130 & .2030 & 2.1010 & 13.1060 & 2.46 & 33.47 \\
\hline 0.25 & 1.4000 & .2890 & 2.2040 & 23.3960 & 3.52 & 45.42 \\
\hline 0.5 & 1.5340 & .4240 & 2.3640 & 35.9740 & 5.21 & 62.13 \\
\hline 1 & 1.6500 & .5400 & 2.5760 & 47.2240 & 6.68 & 72.62 \\
\hline
\end{tabular}

Portfolio with optimal hedge ratio

\begin{tabular}{lrrrrrrr}
0 & 1.1100 & .0000 & .0000 & 2.3000 & -.0000 & .00 & N/A \\
0.025 & 1.1990 & .0890 & .1530 & 8.7000 & -.0200 & 1.07 & 201.51 \\
0.05 & 1.2520 & .1420 & .2680 & 13.3100 & -.0400 & 1.72 & 183.55 \\
0.1 & 1.3300 & .2200 & .4510 & 19.9200 & -.0800 & 2.67 & 168.98 \\
0.25 & 1.4950 & .3850 & .8150 & 31.7900 & -.1600 & 4.72 & 163.64 \\
0.5 & 1.6400 & .5300 & 1.1070 & 4.1500 & -.2100 & 6.55 & 165.85 \\
1 & 1.7360 & .6260 & 1.3410 & 46.2500 & -.2400 & 7.78 & 161.71 \\
\hline
\end{tabular}

Note: Data is based on monthly simulations from March, 1981 to July, 1999. Risk is the level of risk appetite. Monthly portfolio return is actual total return on portfolio in \% per month. Excess return is the actual excess return in \% per month, measured as a difference, 
For simulation set 3 , the hedge ratios are as shown in table 5. At risk 0 , as noted in section 3 , the hedge ratio is zero. It then decreases slowly with increasing risk, reaching a percentage value of $-24 \%$ at the maximum risk level used in the simulations.

When the results of simulation sets 1 and 3 at the same level of risk are compared, optimal hedging offers higher excess return accompanied by an increase in tracking error. However, there is also an increase in the return-risk ratio. This is not as strong a result as the "free lunch" argument suggested in Pérold and Schulmann(1988) in which hedging causes a reduction in volatility without a commensurate reduction in expected return As noted above, this is a consequence of the changing structure of the $V C$ matrix.

The three sets of simulations all display portfolio turnover that increases with risk. The turnover for both hedging strategies is broadly the same at each risk level. The effect of the currency hedge on overall portfolio turnover may be crudely assessed by subtracting the turnover column of set 1 from the same column of sets 2 and 3 . A more detailed analysis, which is not reported here in the interests of space, suggests that, overall, the currency hedge decreases the turnover in real assets. However, as Table 5 shows both hedging strategies cause an overall increase in turnover, a substantial proportion of which is attributable to the hedging.

A detailed analysis of the effect of currency hedging on diversification is also omitted. It is well known that simulations done subject only to non-negativity constraints on the weights of real assets will produce portfolios for which diversification decreases rapidly with risk. In these simulations, the effect of the restrictions on real assets is to preserve most of the diversification even at the highest levels of risk considered.

\section{Concluding Remarks}

This paper describes results that indicate benefits from optimal hedging and, to a lesser extent, from hedging with a fixed overall hedge ratio. Viewed comparatively, the results suggest that the optimal determination of the hedge ratio may always be beneficial. However, as noted by Michaud (1998) and as users of optimization are well aware, this does 
not detract from the requirements for good forecasts. It should also be noted that these findings depend on the structure of the overall VC matrix of returns on assets and currencies.

This study has used mean-variance optimization methods. The empirical evidence reported in section 5 suggests that the presence of both skewness and kurtosis in the distribution of asset returns and forecasts. The effect of these on portfolio selection methods for hedged portfolios is a topic for further work.

\section{Appendix - Efficient Set Mathematics for Portfolios with fixed Hedge Ratios}

When the additional constraint that the currency weights should sum to $h$ is imposed, the first order conditions are:

$$
\theta\left[\begin{array}{l}
\mu_{R} \\
\mu_{C}
\end{array}\right]-\left[\begin{array}{ll}
V_{R R} & V_{R C} \\
V_{C R} & V_{C C}
\end{array}\right]\left[\begin{array}{l}
w_{R} \\
w_{C}
\end{array}\right]-\lambda\left[\begin{array}{l}
1 \\
0
\end{array}\right] \phi\left[\begin{array}{l}
0 \\
1
\end{array}\right]=\left[\begin{array}{l}
0 \\
0
\end{array}\right] .
$$

This has a solution, $\mathbf{w}^{*}$ say, of the form:

$$
\mathbf{w}^{*}=\mathbf{w}+\boldsymbol{\delta}
$$

where $\mathbf{w}$ is the vector of weights obtained for the optimally hedged portfolio in section 3. The vector $\boldsymbol{\delta}$ is given by:

$$
\delta=\left[\begin{array}{ll}
V_{R R} & V_{R C} \\
V_{C R} & V_{C C}
\end{array}\right]^{-1}\left\{\lambda^{\prime}\left[\begin{array}{l}
1 \\
0
\end{array}\right]-\phi\left[\begin{array}{l}
0 \\
1
\end{array}\right]\right\}
$$

Imposing the constraints:

$$
\sum_{i=1}^{N} w_{R, i}=1, \sum_{i=1}^{N} w_{C, i}=h
$$

gives the Lagrange multipliers:

$$
\lambda^{\prime}=-\frac{b}{a} \phi, \phi=\frac{a\left(h-h_{0}\right)}{a c-b^{2}},
$$


where $h_{0}$ is the hedge ratio of the optimally hedged portfolio with weights $\mathbf{w}$ and the constants $a, b$ and $c$ are defined as:

$$
\left[\begin{array}{ll}
a & b \\
b & c
\end{array}\right]=\left[\begin{array}{cc}
1^{T} & 0 \\
0 & 1^{T}
\end{array}\right]\left[\begin{array}{ll}
V_{R R} & V_{R C} \\
V_{C R} & V_{C C}
\end{array}\right]^{-1}\left[\begin{array}{ll}
1 & 0 \\
0 & 1
\end{array}\right]
$$

These are essentially the quantities in Merton (1972) with changes reflecting the different portfolio objective function used here. In this notation, the hedge ratio of the optimally hedged minimum variance portfolio is:

$$
h_{M V}=b / a
$$

Note that $a, c$ and $\left(a c-b^{2}\right)$ are all non-negative and are generally positive. The variance of the fixed hedge portfolio, $V\left[\mathbf{w}^{*}\right]$ say, is related to $V[\mathbf{w}]$, the variance of the optimally hedged portfolio at the same level of risk appetite, by the equation:

$$
V\left[\mathbf{w}^{*}\right]=V[\mathbf{w}]+\frac{a}{\left(a c-b^{2}\right)}\left[\left(h-h_{0}\right)\left(h+h_{0}-2 h_{M V}\right)\right] .
$$

Variance therefore increases or decreases depending on the sign of the quantity in the square brackets.

\section{References}

Anderson, R. W., and Danthine, J.-P. 1981. Cross hedging. Journal of Political Economy 89:1182-1196.

Blattberg, R., and Gonedes, N. 1974. A comparison of the stable and student distributions as statistical models for stock prices. Journal of Business 47:244-280.

Chamberlain, G. 1983. A characterization of the distributions that imply mean variance utility functions. Journal of Economic Theory 29:185-201.

De Roon, F. A.; Nijman, T. E.; and Werker, B. J. M. 2001a. Testing for meanvariance spanning with short sales constraints and transactions costs. Journal of Finance 55:721-742.

De Roon F. A.; Nijman, T. E.; and Werker, B. J. M. 2001a. Currency hedging for international stock portfolios: The usefulness of mean variance analysis. Working Paper. Centre for Economic Research, Tilburg University, The Netherlands.

Eun, C. S., and Resnick, B. G. 1988. Exchange rate uncertainty, forward contracts and international portfolio selection. Journal of Finance 43:197-215. 
Frost, P., and Savarino, J. 1988. For better performance constrain the weights. Journal of Portfolio Management 14:29-34.

Gibbons, M.; Ross, S.; and Shanken, J. 1989. A test on the efficiency of a given portfolio. Econometrica 57:1121-1152.

Glen, J., and Jorion, P. 1993. Currency hedging for international portfolios. Journal of Finance 48:1865-1886.

Huberman, G., and Kandel, S. 1987. Mean variance spanning. Journal of Finance 42:873-888.

Jobson, J. D., and Korkie, B. 1984. On the Jensen measure and marginal improvements in portfolio performance: A note. Journal of Finance 39:245251.

Johnson, N. L., and Kotz, S. 1970. Continuous univariate distributions-2. Boston:Houghton-Mifflin.

Ingersoll, J. E. 1987. The theory of financial decision making. Savage: Rowman and Littlefield.

Merton, R. C. 1972. An analytic derivation of the efficient portfolio frontier. Journal of Financial and Quantitative Analysis 7:1851-1872.

Michaud, R. O. 1998. Efficient asset management. Boston:Harvard Business School Press.

Pérold, A., and Schulmann, E. 1988. The free lunch in currency hedging: Implications for investment policy and performance standards. Financial Analysts Journal, 44:45-50.

Praetz, P. 1972. The distribution of share price changes. Journal of Business, 45:49-55.

Rustem, B. 1997. Computing optimal multi-currency mean-variance portfolios. Forecasting Financial Markets Conference, London.

Solnik, B. 1999. International investments. Fourth Edition. Reading:Addison Wesley.

Stevens, G. V. G. 1998. On the inverse of the covariance matrix in portfolio analysis. Journal of Finance, 53:1821-1827. 